\title{
Disección anatómica de la musculatura mímica facial: revisión iconográfica de apoyo a los tratamientos complementarios en rejuvenecimiento facial Anatomical dissection of the mimic facial musculature: iconographic review as a support to the complementary treatments in facial rejuvenation
}

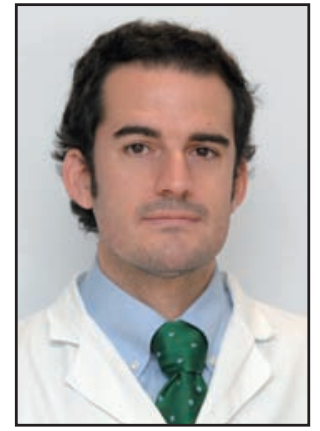

Casado Sánchez, C.

\author{
Casado Sánchez, C.*, Martínez Méndez, J.R.*, Álvarez García-Peñuela, S.**, \\ Bonastre Juliá, J.**, Clascá Cabré, F.**, Casado Pérez, C.***
}

\section{Resumen}

A la hora de valorar las múltiples técnicas empleadas en el rejuvenecimiento facial y centrándonos de manera particular en aquellos procedimientos mínimamente invasivos complementarios a las intervenciones habituales en Cirugía Plástica-Estética, cobra especial relevancia el conocimiento exhaustivo de las estructuras musculares implicadas en la mímica facial. A tal efecto, se ha realizado un estudio anatómico en cadáveres frescos, en los que se han disecado las principales estructuras referidas. Se presenta un resumen iconográfico de los músculos faciales implicados, haciendo hincapié en su anatomía descriptiva y funcional, así como un recuerdo de las principales áreas problemáticas por alguna circunstancia especial (presencia de un nervio sensitivo o motor).
Palabras clave Anatomía facial, Disección anatómica,

Rejuvenecimiento facial

Código numérico 10-2-26-263-266
To value the multiple technologies involved in facial rejuvenation and focusing in those minimally invasive complementary procedures to the usual Plastic and Aesthetic Surgeries, it's very important the exhaustive knowledge of the muscular structures involved in the facial movements. To such an effect, an anatomical study has been realized in fresh corpses, dissecting the principal above-mentioned structures. We present an iconographic summary of the facial implied muscles, emphasizing in his descriptive and functional anatomy, as well as a recollection of the principal problematic areas for some special circumstance (presence of a sensory or motor nerve).

\begin{tabular}{ll}
\hline Key words & $\begin{array}{l}\text { Facial anatomy, Anatomical dissection, } \\
\text { Facial rejuvenation }\end{array}$ \\
Numeral Code & $10-2-26-263-266$
\end{tabular}

* Especialista en Cirugía Plástica, Servicio de Cirugía Plástica y Quemados, Hospital Universitario La Paz, Madrid, España

** Médico Interno Residente, Servicio de Cirugía Plástica y Quemados, Hospital Universitario La Paz, Madrid, España

*** Catedrático de Anatomía y Embriología Humana. Departamento de Anatomía, Histología y Neurociencia. Facultad de Medicina, Universidad Autónoma de Madrid. España

**** Jefe de Servicio de Cirugía Plástica y Quemados, Hospital Universitario La Paz, Madrid, España 


\section{Introducción}

La disección en cadáver ha pasado de ser una práctica habitual en la formación quirúrgica de los especialistas en Cirugía Plástica, Estética y Reparadora una actividad prácticamente excepcional desarrollada tan solo en algunos talleres o cursos. Los esquemas recogidos en los atlas anatómicos suponen un soporte importante en el conocimiento de las estructuras, pero debería basarse primero en imágenes reales y en la práctica y disección en cadáver.

Conocer e identificar adecuadamente las estructuras musculares, vasculares y nerviosas faciales, constituyen la base del éxito en la aplicación de todos los procedimientos de Cirugía Reparadora y Estética a este nivel. En los últimos años, la aparición de técnicas mínimamente invasivas complementarias en Cirugía Plástica-Estética, como el uso de materiales de infiltración empleados en rejuvenecimiento facial, hacen más necesario aún si cabe el recurrir a la disección anatómica para conocer con mayor exactitud distintos aspectos, por ejemplo los puntos de infiltración, los límites de las áreas más comprometidas o la distribución de las diferentes ramas nerviosas. Estos conocimientos anatómicos más precisos nos permiten afrontar con mayor seguridad estos procedimientos, poder anticipar los efectos de nuestros tratamientos y proporcionar así resultados más satisfactorios a nuestros pacientes.

El presente artículo pretende ser un breve resumen iconográfico de la musculatura mímica facial y de otros aspectos relevantes en procedimientos auxiliares en $\mathrm{Ci}$ rugía Plástica facial.

Para ello, nos hemos planteado la disección anatómica en cadáver de la musculatura mímica facial, así como su relación con las principales estructuras nerviosas (sensitivas y motoras) a este nivel.

\section{Material y método}

Empleamos cadáveres frescos de donantes en los que se registró el éxitus entre 24 a 72 horas antes de la práctica, conservados en cámaras refrigeradas a $4^{\circ} \mathrm{C}$. Realizamos una disección subcutánea de la musculatura mímica facial a través de una incisión hemifacial que se extiende a nivel posterior de la rama mandibular, preauricular y en la línea capilar témporofrontal e incisiones cutáneas periféricas a nivel hemibucal, palpebral y de narina homolaterales (Fig. 1 y 2). En uno de los cadáveres se realizó una incisión cutánea en el eje longitudinal desde el punto medio súperofrontal hasta el punto medio mentoniano. Identificamos los músculos responsables de la mímica facial, las ramas sensitivas periféricas del nervio trigémino (par craneal número $\mathrm{V}$ ) y las ramas motoras periféricas del nervio facial (par craneal número VII). Una vez realizada la disección anatómica, se procedió a la reposición y cierre cutáneo. Tras esto, los cadáveres
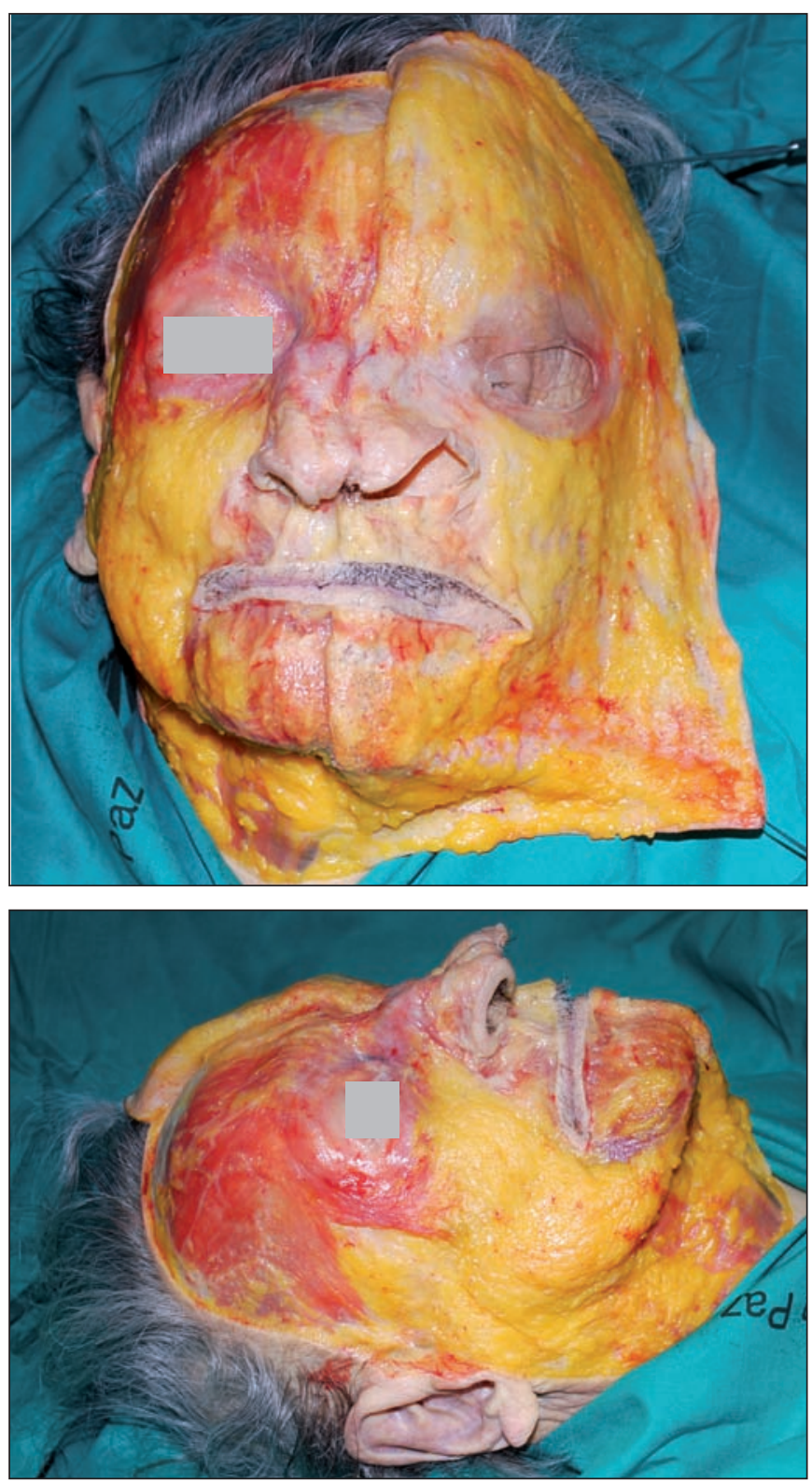

Fig. 1 y 2: Preparaciones anatómicas.

fueron tratados para su conservación (formol diluído en agua al $10 \%$ y una preparación antifúngica de óxido de antimonio) y preservados a $4^{\circ} \mathrm{C}$.

\section{Anatomía descriptiva y presentación de imágenes}

Los músculos responsables de la expresión facial se desarrollan a partir del segundo arco branquial o faríngeo (denominado arco hioideo), como parte de la lámina muscular subcutánea que forma el platisma y su extensión facial. Todos estos músculos reciben su inervación motora del nervio facial (VII par craneal). Además, la piel suprayacente, recibe su inervación sensitiva a partir del nervio trigémino ( $V$ par craneal). Es importante señalar que los músculos dependientes del nervio trigémino (músculos de la masticación) se desarrollan a partir del primer arco branquial (o arco mandibular).

Describimos a continuación y de forma breve los mús- 
culos implicados en la mímica facial, apoyados con la iconografía de cada uno de ellos (1-6).

El músculo frontal (Venter Frontalis del M. Occipitofrontalis) forma parte del músculo del cuero cabelludo denominado occipitofrontal, constituyendo la porción anterior de éste. Se extiende desde la aponeurosis epicraneal a nivel del vertex craneal hasta las cejas, posibilitando la elevación de éstas, y produciendo así una mirada de sorpresa. De esta forma provoca las arrugas transversales de la frente al fruncir el ceño (Fig. 3).

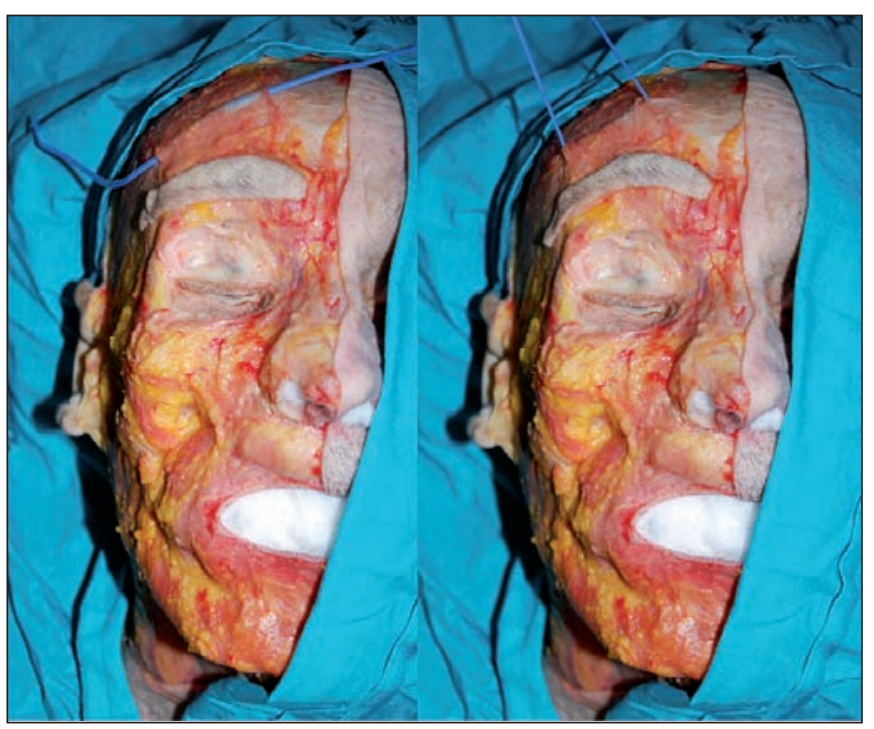

Fig. 3: Músculo frontal.

El músculo prócero o piramidal de la nariz ( $M$. Procerus) es una pequeña tira muscular que se continúa con el músculo occípitofrontal. Se dirige desde la región frontal central, pasando por la raíz nasal o puente nasal, donde se inserta en la piel situada a nivel de la glabela. Tracciona hacia abajo de la porción inferior de la ceja, causando arrugas transversales sobre el puente nasal (Fig. 4).

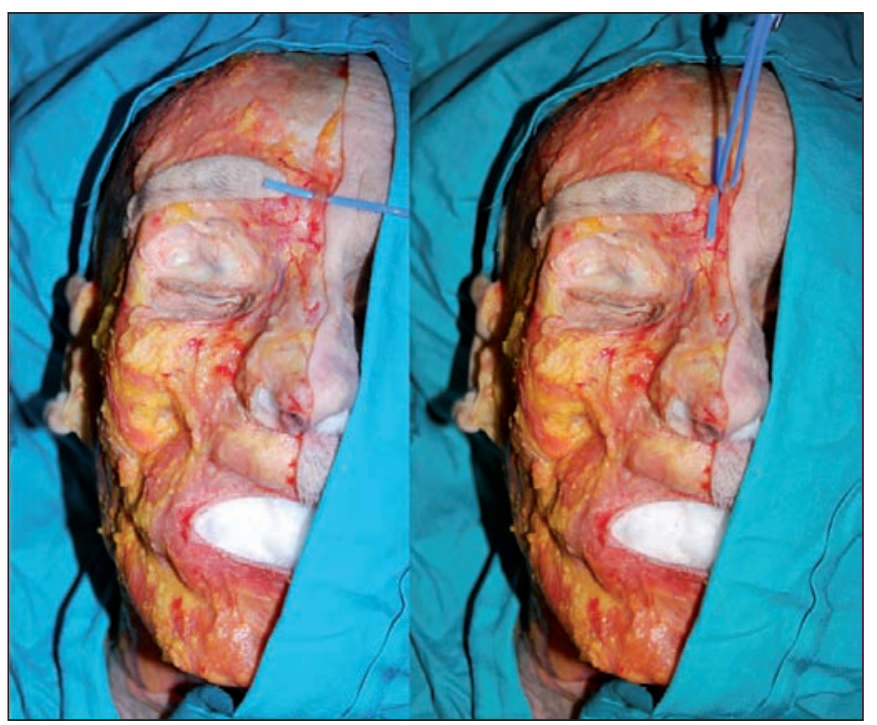

Fig. 4: Músculo prócero o piramidal.
El músculo corrugador de la ceja o superciliar $(M$. Corrugator Supercilii) se origina en la porción nasal del frontal y se inserta lateralmente a nivel cutáneo en la región del tercio medio de la ceja, con una mayor o menor extensión, ubicándose bajo el orbicular de los ojos y el propio músculo frontal. Mediante su contracción, origina arrugas verticales a nivel de la glabela y por encima de ambas cejas (Fig. 5).

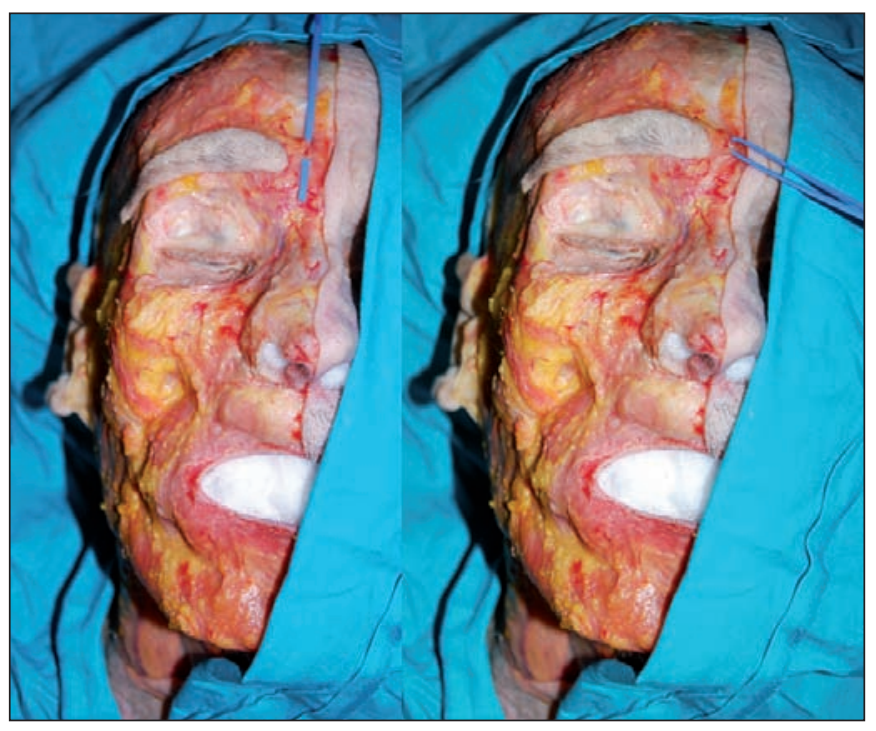

Fig. 5: Músculo corrugador o superciliar.

El músculo elevador del labio superior y del ala nasal (M. Levator Labii Superioris Alaeque Nasi) se inserta cranealmente en el maxilar, dividiéndose en dos porciones musculares que se insertan en el cartílago alar y en el labio superior, elevando ambas estructuras (Fig. 6 y 7).

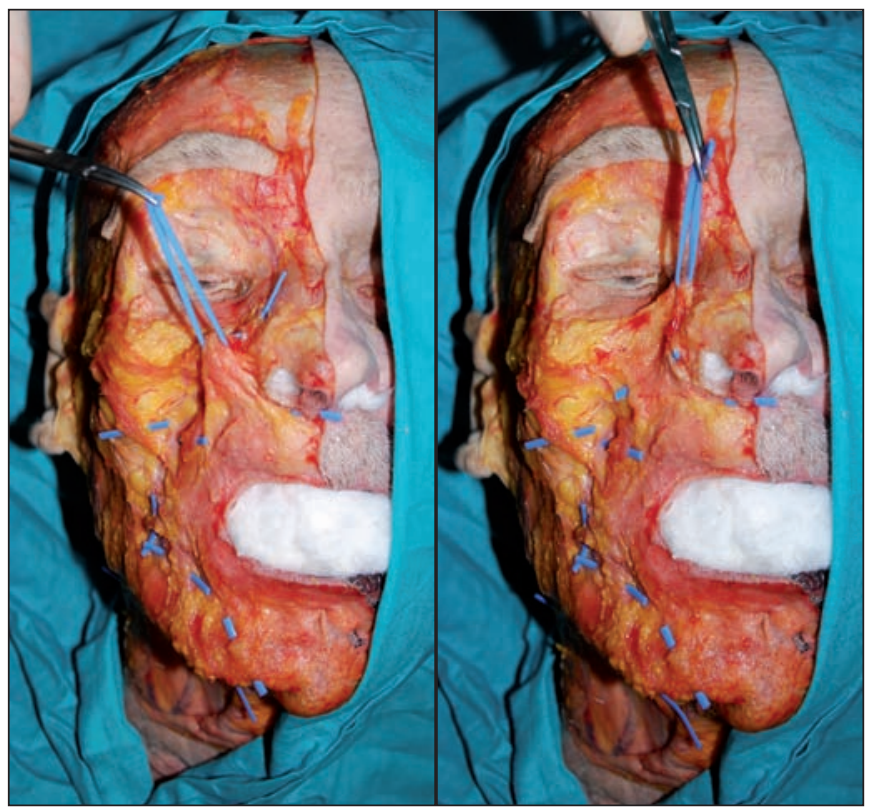

Fig. 6: Músculo elevador del labio superior.

Fig. 7: Músculo elevador del ala nasal. 
El músculo elevador del ángulo de la boca $(M$. Levator Labii Superioris) se origina en el borde infraorbitario, insertándose en el ángulo de la boca (Fig. 8).

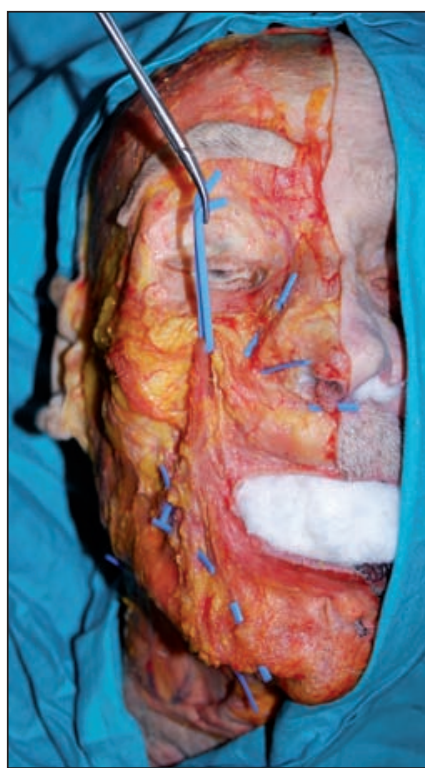

Fig. 8: Músculo elevador del ángulo de la boca.

El músculo cigomático mayor (M. Zygomaticus Major) se extiende desde el borde lateral del hueso cigomático hasta el ángulo de la boca, traccionando súperolateralmente de él durante las expresiones de risa o sonrisa (Fig. 9).

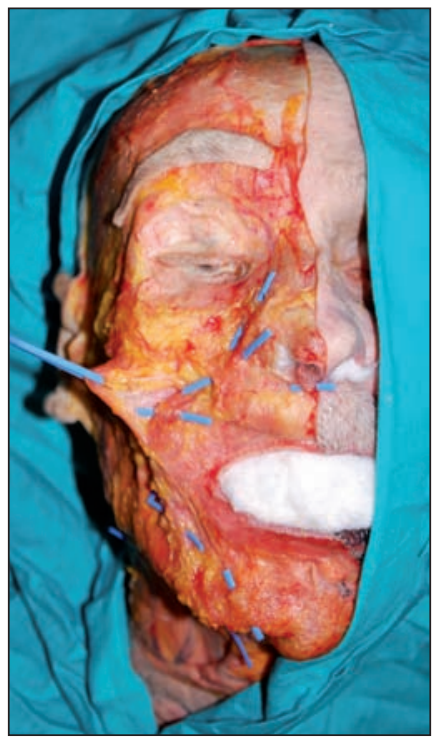

Fig. 9: Músculo cigomático mayor.

El músculo cigomático menor (M. Zygomaticus Minor) se dirige oblicuamente desde el segmento anterior del hueso cigomático hasta músculo orbicular de la boca, contribuyendo a la elevación del ángulo oral.

El músculo risorio (M. Risorius) es un músculo variable, relacionado íntimamente con el platisma. Se inserta en la fascia parotídea y se dirige al ángulo de la boca, traccionando lateralmente de la comisura labial al sonreír (Fig 10).

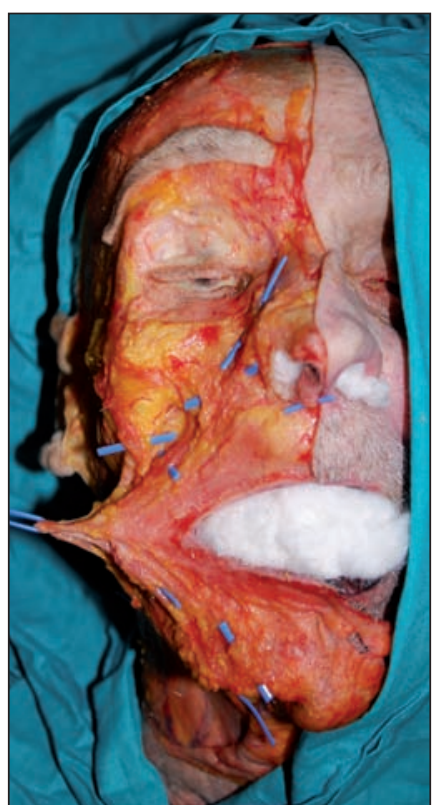

Fig. 10: Músculo risorio.

El músculo depresor del tabique nasal o mirtiforme (M. Depressor Septi) se origina cranealmente en los incisivos centrales y se inserta a nivel del tabique nasal cartilaginoso, provocando mediante su contracción un descenso del vértice nasal (Fig. 11).

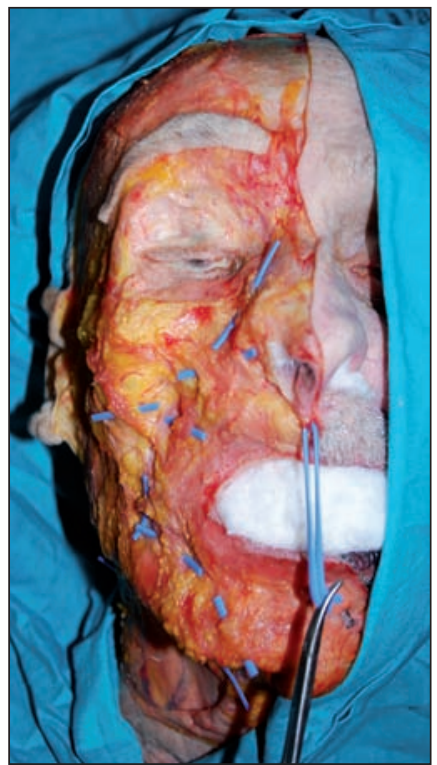

Fig. 11: Músculo depresor del tabique nasal mirtiforme.

El músculo depresor del ángulo de la boca $o$ triangular $(M$. Depressor Anguli Oris, M. Triangularis) deprime, como su propio nombre indica, el ángulo oral. Las fibras posteriores del platisma contribuyen también a este movimiento. Se origina a nivel de la porción anterolateral de la mandíbula, insertándose en el ángulo de la boca (Fig. 12).

Fig. 12: Músculo superior del ángulo de la boca o triangular.

El músculo mental o mentoniano (M. Mentalis) es un pequeño músculo que se inserta en la mandíbula, sobre las raíces de los incisivos inferiores y desciende para insertarse en la piel del mentón. Eleva la piel de la barbilla, como sucede por ejemplo al expresar duda (Fig. 13).
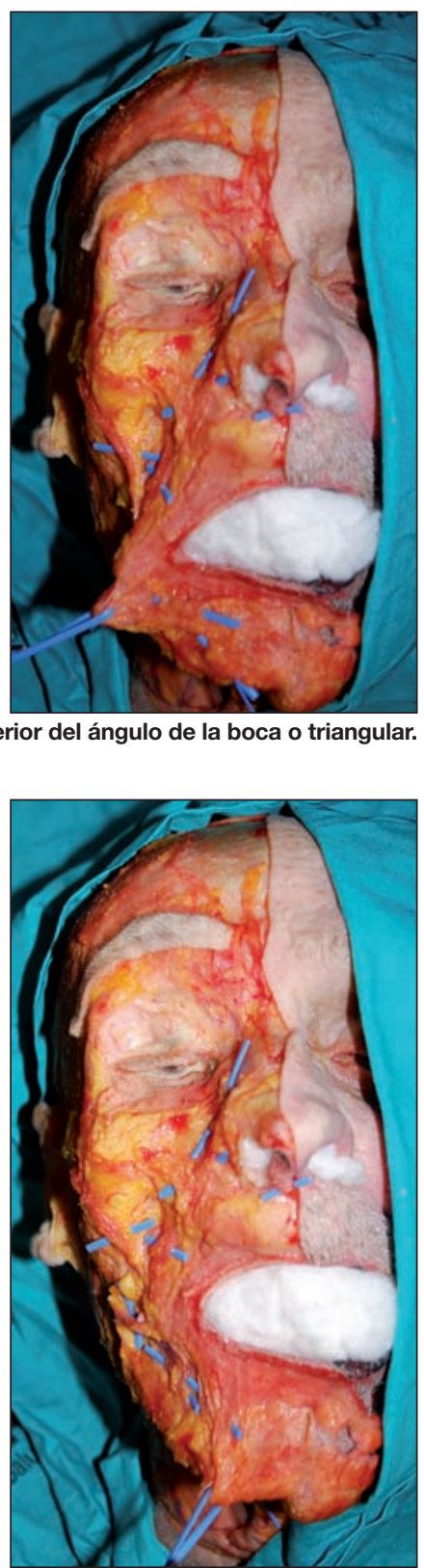

Fig. 13: Músculo mental o mentoniano. 


\begin{abstract}
El músculo depresor del labio inferior $(M . D e$ pressor Labii Inferioris) se sitúa lateral al músculo mental y medial y parcialmente inferior al músculo depresor del ángulo de la boca, uniéndose por arriba con el músculo depresor del labio inferior contralateral y el músculo orbicular de la boca. Tracciona del labio en sentido inferior y discretamente lateral, como ocurre al mostrar impaciencia (Fig. 14).
\end{abstract}

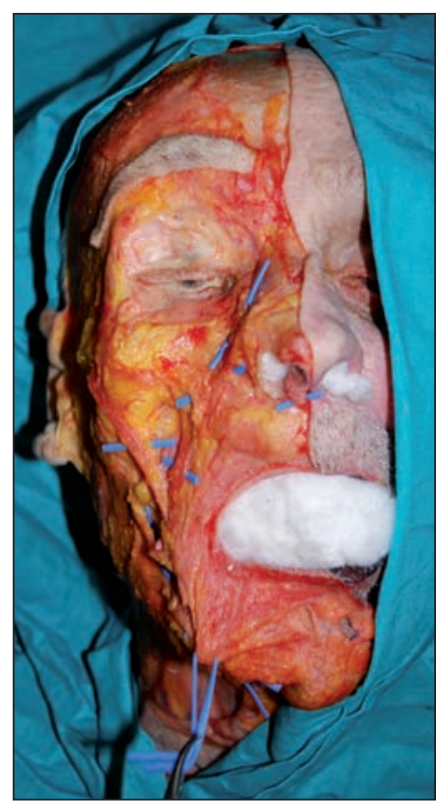

Fig. 14: Músculo depresor del labio inferior.

El conjunto de todas estas estructuras musculares reciben su inervación motora del nervio facial (VII par craneal). Hemos de tener en cuenta que dentro de las ramas de este nervio, debemos destacar dos especialmente superficiales (Fig. 15). Por un lado, la rama temporal, localizada en un área limitada por una línea trazada sobre el arco cigomático y otra que discurre desde el trago hasta $2 \mathrm{~cm}$. por encima de la cola de la ceja. Su lesión podría no afectar al músculo orbicular de los ojos (dada su doble inervación por las ramas cigomáticas), aunque conllevaría ptosis de la cola de la ceja por la parálisis del músculo frontal. Por otra parte, la rama marginal, localizada dentro de un círculo imaginario de $4 \mathrm{~cm}$. de diámetro, cuyo centro se sitúa $3 \mathrm{~cm}$. posterior e inferior a la comisura bucal. Situada superficial a la arteria y vena faciales, su lesión impediría mostrar los dientes inferiores del lado afecto.

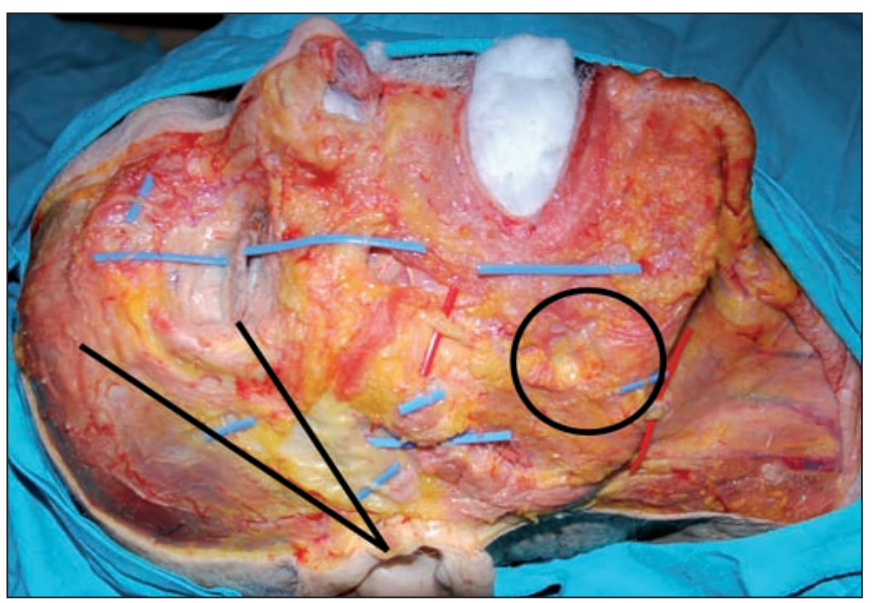

Fig. 15: Ramas temporal y marginal del nervio facial (VII par craneal).

Señalar finalmente que los nervios sensitivos faciales (Fig. 16), dependientes del nervio trigémino, se localizan en una línea que atravesaría la pupila y la comisura

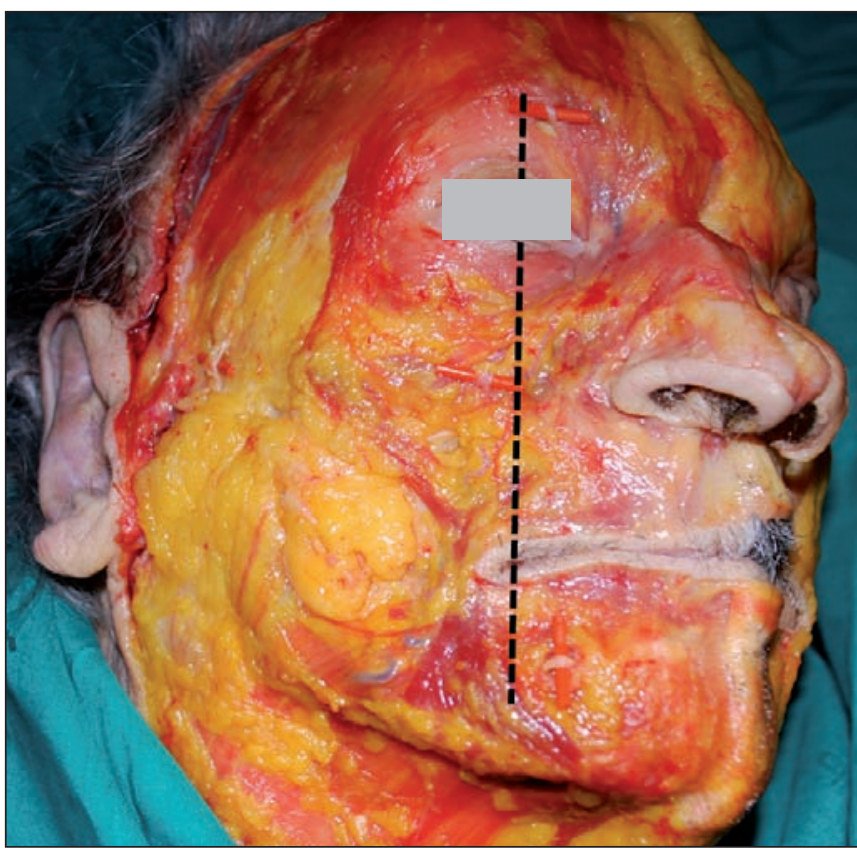

Fig. 16: Línea de localización de los nervios sensitivos faciales: supraorbitario, infraorbitario y mentoniano.

oral (supraorbitario, infraorbitario y mentoniano). Por tanto, son fácilmente accesibles para realizar un bloqueo nervioso, de forma transcutánea el supraorbitario (fácil palpación de la escotadura supraorbitaria) o mediante abordaje oral el infraorbitaio (localizable en una línea que une el canino con la pupila) y el mentoniano (a nivel inferior al segundo premolar inferior).

\section{Conclusiones}

El conocimiento preciso de las estructuras implicadas en la mímica facial, es uno de los pilares en los que se basa la correcta aplicación de las técnicas complementarias del rejuvenecimiento facial. Los numerosos nervios y músculos responsables son fácilmente identificables mediante una disección anatómica cuidadosa. La práctica en cadáver es aquí, como en otros procedimientos quirúrgicos, igualmente importante para conseguir resultados satisfactorios. En este sentido, consideramos relevante la formación en sala de disección durante la residencia o el reciclaje como especialista, de todo cirujano plástico que aplique estas técnicas.

\section{Dirección del autor}

Dr. César Casado Sánchez

Servicio de Cirugía Plástica y Quemados

Hospital Universitario La Paz

$\mathrm{P}^{\mathrm{o}}$ de la Castellana 261, 28046 Madrid. España.

e-mail: doctorcasado@gmail.com

\section{Agradecimientos}

A D. Andrés Olaya, celador de la sala de disección de la Facultad de Medicina de la Universidad Autónoma de Madrid, por su trabajo y disposición. 


\section{Bibliografía}

1. Sobotta J.: "Atlas de Anatomía Humana. Vol I". $20^{\mathrm{a}}$ ed. Editorial Médica Panamericana, Madrid, España, 1994. Pp: 70-75.

2. Netter FH.: "Atlas of Human Anatomy". $1^{\mathrm{a}}$ ed. CibaGeygi Corporation, Basilea, Suiza, 1989. Pp: 18-21.

3. Feneis H.; "Nomenclatura anatómica ilustrada". $3^{\mathrm{a}}$ ed. Masson, Barcelona, España, 1994. Pp: 78, 320-329.
4. Moore KL.: “Anatomía con orientación clínica”. $3^{\mathrm{a}}$ ed. Editorial Médica Panamericana, Madrid, España, 1993. Pp: 683-691.

5. Giacomotti JD, Bertone VH, Conesa HA, Ouviña JM, Seiler JI, Ottone NE, Dominguez ML, Arrotea A.: "Nuevos conceptos sobre el sistema muscular peribucal". Cir. plást. iberolatinoam. 2009, 35 (2): 101.

6. Sadler TW.: "Embriología médica de Langman". $7^{\mathrm{a}}$ ed. Editorial Médica Panamericana, Madrid, España, 1996. Pp: 293-296. 